\title{
Self-starting of pump units when extinguishing voltage in the energy saving mode
}

\author{
Kudrat Abidov ${ }^{1}$, Odiljon Zaripov ${ }^{2}$ \\ ${ }^{1}$ Head of Department, Tashkent State Technical University, Tashkent, Universitetskaya str. 2, Uzbekistan \\ ${ }^{2}$ Assistant, Tashkent State Technical University, Tashkent, Universitetskaya str.2, Uzbekistan
}

\begin{abstract}
The article discusses the main processes that occur during the self-start of pumping units of pumping stations of systems of machine lifting for irrigation, ensuring the rational use of electricity, pumping equipment and irrigation water.
\end{abstract}

\section{Introduction}

One of the main consumers of electricity in Uzbekistan is the pumping stations of the agricultural industry. Of the generated 47 billion $\mathrm{kWh} /$ year of electricity, an average of 8 billion $\mathrm{kWh} /$ year or about $16 \%$ is spent on covering the loads of 1,588 state reclamation pumping stations, which are currently on the balance sheet of the Ministry of Agriculture and Water Resources of the Republic of Uzbekistan. In recent years, the everincreasing number of small pumping stations owned by farms and tenants has led to the fact that the energy costs of pumping stations are becoming even more significant.

The use of pumping units, taking into account the specific features of irrigated agriculture, made it possible to solve complex engineering and reclamation problems. The construction and commissioning of large machine channels with unique cascades of pumping stations and complex hydraulic structures made it possible to transfer the flow of high-water rivers to large irrigated massifs located in the lower reaches of the low-water rivers Zarafshan, Kashkadarya, Surkhandarya, Isfayramsay, etc., where there is a lack of water and systematically repeated water impeded the development of agriculture $[1,2]$.

With the help of pumping stations, 2.418 million hectares of 4.3 hectares of irrigated land are currently irrigated. About 59 billion $\mathrm{m} 3$ of irrigation water is pumped annually with all pumps, with 27 billion m3 being pumped by the head pumping stations, and 32 billion $\mathrm{m} 3$ by the second and subsequent rises.

The largest pumping stations were built and commissioned in the complex of Amu-Bukhara, Sherabad, Karshi, Dzhizak, Amu-Zang machine channels, which made it possible to sharply increase the water supply of irrigated lands and master hundreds of thousands of hectares of new lands. About 2,000 m3 / s of water is pumped by pumps only in these five channels, and the power of the main electric motors is 1.2 million $\mathrm{kW}$.
As you know, transients are more dangerous for electrical equipment, including a pump installation, than established ones. The main damages and accidents of pumping units occur during transients, starts, stops, which, in accordance with the work schedule, can be assigned several times a day, as well as during emergency disconnection of electric motors from the power system. Significant dynamic loads arise on the elements of structures and hydro-power equipment: water hammer, a sharp change in the power effects on the impeller and the blade drive systems, accompanied by flow pulsations, vibration. Therefore, when operating pumping stations, it is necessary to comprehensively take into account the work of the pressure path and technological equipment and assign schemes and the composition of structures based on calculations and analysis of transients taking into account the static and dynamic characteristics of pumps and electric motors.

\section{Experimental research}

Pumping units of an open irrigation system operate on pipelines of relatively short lengths ending in siphon outlets. With a planned shutdown of the pump unit, the control valve closes at the beginning, then the drive motor is disconnected from the network. Due to this, the pump unit stops and does not rotate in the opposite direction.

During $[3,4]$ emergency shutdowns due to the fact that the control valve is not closed, when there is no check valve or it does not work, the water in the pipeline will go back after shutting down the unit. At the beginning, the speed of the unit decreases and reaches zero, then under the influence of water in the pipeline it changes direction, it rotates in the opposite direction and the value of the reverse stealing speed becomes more than the nominal value. When the pump rotates in the opposite direction, the pump seals fail. This leads to a violation of the pump sealing system. Therefore, after 
this mode, before starting the pump, the plugs of the pump are removed, the burnt out oil seals are removed, and new oil seals are clogged. The vacuum pump is started to prepare the pump for start-up, since the control valve does not close tightly, filling the collector with water is required.

The number of installed pumping units at reclamation pumping stations varies widely (2-16 pieces). The pump drive motors are powered by a step-down substation of the pumping station. Two-winding and three-winding transformers are used at these substations. The number of simultaneously self-starting motors of the pumping station is determined based on the permissible value of the voltage drop at the time of self-starting. Knowing the mains voltage and the resistance of the power source, we determine the value of the recovery voltage on the motors.

When the pumps are of vertical design, axial, where there are no gates, any voltage deviation is associated with rotation in the opposite direction, which negatively affects the operation of the thrust bearing, the fastenings of the pump and motor windings. All this is associated with the consumption of scarce materials, it requires a lot of time and qualified repairmen. If the pump works with suction, then during a power outage it may lose water, turn on empty. Experience shows that the loss of a column of water occurs, as a rule, only when the speed drops below $50 \%$. After each cancellation or landing of the mains voltage, the pumps are switched off. It takes a long time to restore the station to its original working condition. A simple pumping station during an intensive irrigation period is unacceptable, therefore, it is of great technical and economic importance to reduce the downtime of pumping units of the pumping station using self-starting. Calculations of self-starting currents of induction motors must be performed both during design and during operation of electric power facilities.

When power is applied, self-starting motors of auxiliary motors are operated when the rotation frequency increases. Self-starting will be successful if the pumping units participating in this mode are deployed to the operating speed in an acceptable time. The success of self-start depends on the time of a power outage, the parameters of the supply circuit, the total power of the disconnected motors and their load, the mechanical characteristics of the mechanisms and other factors.

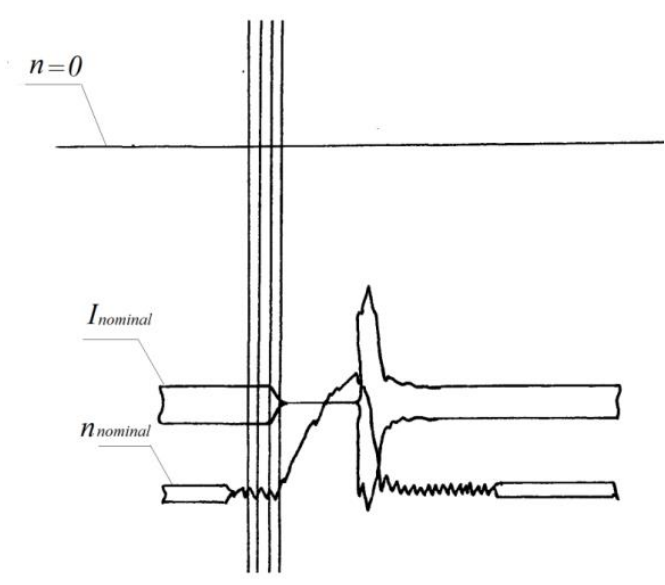

Fig.1. Self-starting at $t_{\text {shutdown }}=1.5 \mathrm{~s}$

In all cases, self-start must be justified. The main task of self-start-up is to maintain the efficiency of the pumping station with short-term repayment. If the capacity of the power supply system is sufficient, all pumping units for which it is necessary can participate in the simultaneous self-start. If the limited capacity of the power supply system does not allow this, then several stages of self-start are provided, that is, alternate selfstart of several groups of pumping units. In this case, the question also arises of the mutual influence of the power supply system and the engines of pumping units involved in self-starting. A more significant limitation in the use of self-starting pumping installations is caused by the fear of the possibility of water hammer in the pressure pipe when the loaded pump is suddenly turned on.

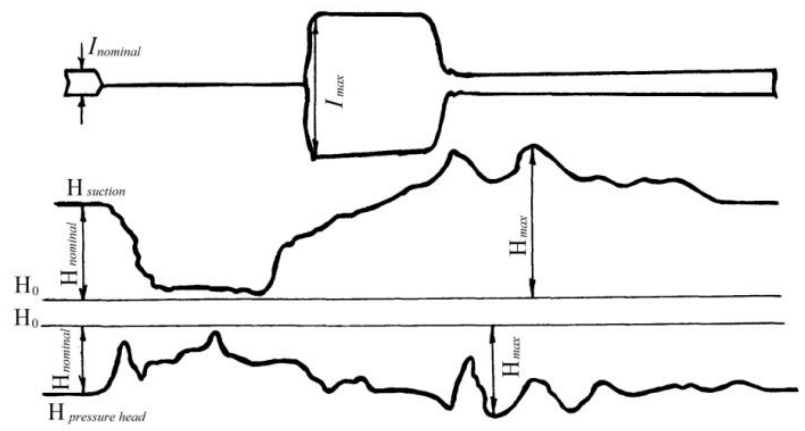

Fig.2. Self-start when $t_{\text {shutdown }}=4.5 \mathrm{~s}$

In the proposed work, the time of the on state of the engine during repayments is determined using a sensor recording a pressure gauge installed at the pump outlet (Fig. 1) or by calculation based on four square characteristics of the pump and parameters of the pump installation. The self-starting zone is in the range of the pressure change from the nominal value to the minimum value. In this work, after the repayment, the disappearance of the voltage in the network, it is possible to determine the allowable area of the engine selfstarting based on 
a) design data of the pumping station and the four square characteristics of the pump (by calculation);

b) pressure measurement using sensors or a recording pressure gauge installed at the pump outlet (to increase accuracy) or a reference pressure gauge (Fig. 2);

d) the characteristics of the run-out of the pump unit, which determine the zone for successful self-start (Fig. $3)$.

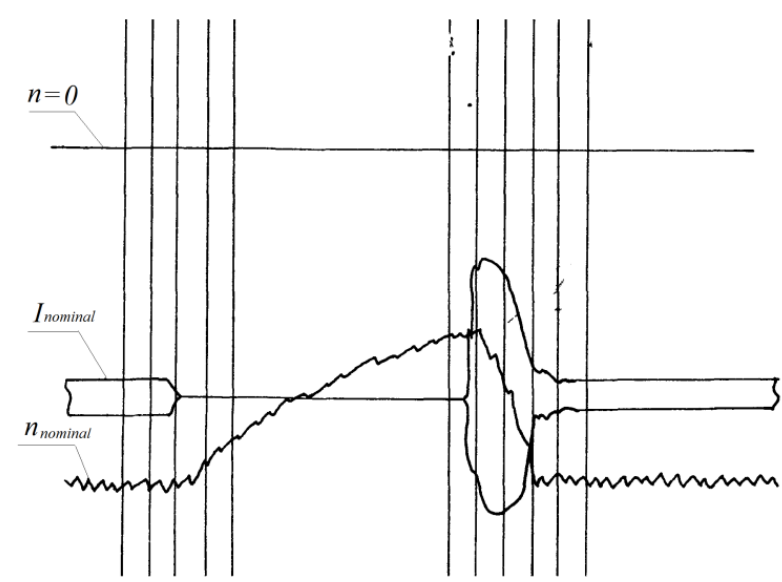

Fig. 3. Self-starting at $t_{\text {shutdown }}=2.2 \mathrm{~s}$

The reliability of the pump unit as a whole is increased, downtime is reduced, and the consumption of scarce materials is reduced. Using the method allows you to free the labor of skilled workers or specialists, because there is no chance of an emergency at pumping stations [7.8].

High-voltage power lines of Amu-Zang pumping stations and electric motors are operated in difficult climatic conditions. During the irrigation season, there is a decrease in the mains voltage and a short-term decrease in the mains voltage. This leads to the shutdown of all pumping units of pumping stations $[9,10]$.

The pumping station of the first lift is equipped with horizontal centrifugal pumps of the $24 \mathrm{HДС} \mathrm{type} \mathrm{with} \mathrm{a}$ turned impeller diameter $\mathrm{D}_{\mathrm{RC}}=375 \mathrm{~mm}$. As a drive motor, three-phase asynchronous motors of the ДАЗО type were used.

The first stage pumping station consists of $1624 \mathrm{HДС}$ pumps with an impeller diameter of $875 \mathrm{~mm}$ and ДАЗО $-15-59-10$ asynchronous motors in the same quantity.

The pumping station of the second stage consists of similar pumps $\left(24 \mathrm{H} Д \mathrm{C}\right.$ with $\left.\mathrm{D}_{\mathrm{RC}}=375 \mathrm{~mm}\right)$ in the same amount of 16 pieces, but ДАЗО-15-69-10 electric motors were used as an electric drive. All of these pumping station motors are powered by a single substation. These motors are powered by transformer No. 1 type ТДТН-2500/110/6/6.

Experimental oscillograms of the self-start process in field conditions were taken at the Amu-Zang pump station of the 1st lift of the 2nd stage. Self-starting processes of one pumping unit No. 11 were oscillated at various values of the time delay, which varied from 1.53 seconds. The pump rotation speed, stator current I, run- out time and self-start time were recorded. The results of the oscillogram of a field study are shown in Fig. 1. and fig. 3. The oscillogram shows that the multiplicity of the starting current and the duration of the self-start increase with increasing repayment time.

\section{Design Studies}

A number of programs for calculating the specified mode for industrial enterprises have been developed, that is, development is taking the path of programmatically implementing the mathematical model $[5,6]$. Organizations involved in this area use different methods of software implementation. The calculation of the processes occurring in such systems can be represented in the form of nonlinear equations describing the operation of pumping units for an individual and common pipeline, and the loss of electrical energy to overcome hydraulic resistance in pipelines under various conditions.

To calculate the mode, a mathematical model of the pumping unit was developed to study the operating modes of the pumping station. The specifics of transients in pumping stations is the loss of drive. As a typical example in Fig. 4. The calculated process curve after the loss of the drive of the Amu-Zang pumping station in the Surkhandarya region of the Republic of Uzbekistan is given.

At time "a", the engine was disconnected from the mains and its $\mathrm{M}_{\text {eng }}$ moment instantly drops to zero, while the hydraulic moment of resistance of the $M_{\text {pum }}$ pump remains. This leads to a decrease in the rotational speed $\mathrm{n}$ and the developed head $\mathrm{H}$, which results in a decrease in the supplied flow rate $\mathrm{Q}_{\mathrm{H}}$.

At time "b", the rotation frequency decreases so much that the flow rate becomes equal to zero, and then the movement of water through the pipelines and the impeller from the upstream to the downstream, i.e. in the "turbine" direction. The direction of rotation is still kept "pumping". This is a counterflow mode. Due to the fact that in this mode the pump capacity drops sharply, there is an increase in pressure in the spiral chamber, pressure, as well as hydraulic torque. 


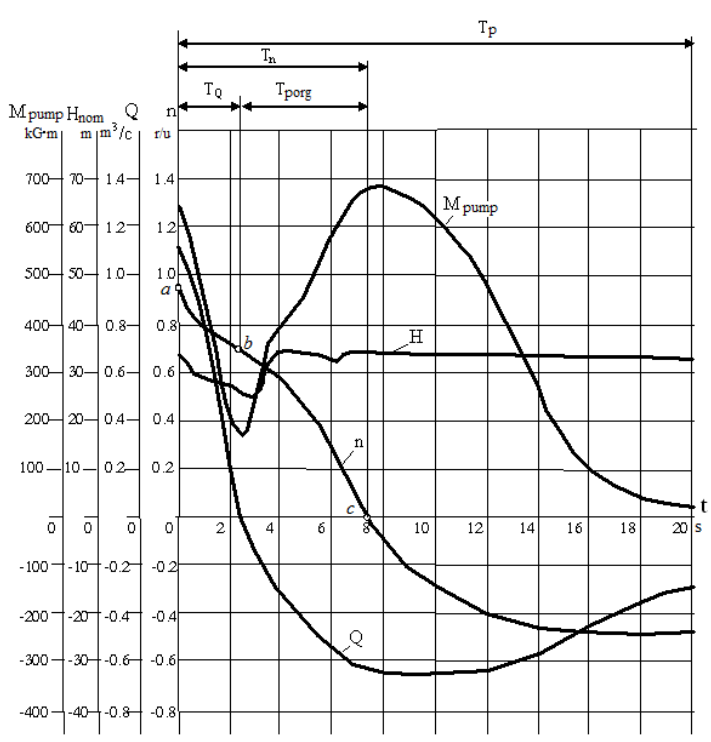

Fig. 4. The nature of the transition process when turning off the electric motor.

At time "c", the rotation frequency becomes equal to zero, and then, under the influence of the flow, the impeller begins to rotate in the opposite direction. The hydraulic torque reaches its maximum value and begins to decline. When reaching $\mathrm{M}_{\text {pum }}=0$, a steady acceleration mode occurs. The speed and flow rate are determined by the impeller, pressure and position of the guide vanes.

The above shows that the loss of the drive of the unit is accompanied by intense dynamic effects on pressure pipelines and equipment elements, which can be limited by choosing the optimal control mode. This must be taken into account when designing pumping stations.

\section{Conclusion}

1. The increase in the exposure time leads to an increase in the frequency of the starting current and the duration of the start. The results of field studies show that the minimum starting current will be with a decrease in the repayment time to $1.5-2$ seconds. The shorter the power interruption, the less the motors have time to brake, the lower their starting currents and the greater the initial voltage on the tires after switching on the backup power and, therefore, the faster the motors start self-starting.

2. The materials of the article and the recommendations expressed in it can be the basis for innovative projects dedicated to improving the operational reliability and energy efficiency of electric motors for drives of pumping units.

\section{References}

1. V.KH. Georgiadi, Behavior of TPP power units during interruptions in power supply for their own needs, in Russian ( NTF Energoprogress 2. 88, 2003)

2. V.I. Vissarionov, Energy equipment for the use of alternative and renewable energy sources, in Russian (RES Publishing House 448,2004)

3. O.Y. Glovatsky, R.R.Ergashev, B.KH.Norov, Failure Analysis of Elements of Machine Water-Raising Systems, in Uzbekistan (Materials of the TIIM International Conference November, 27,2008)

4. O.Y.Glovatsky, A.A. Gufranov, B.R. Uralov, Ergashev R.R. Improving the reliability of operation of water supply facilities of large pumping stations, in Uzbekistan (Materials of the international conference TIIM November, 29, 2008)

5. T.S.Kamalov, K.Muminov, O.KH.Ishnazarov, Transmission coefficient of a functional converter of an asynchronous electric drive system with frequency control, in Uzbekistan (Uzbek magazine "Problems of Informatics and Energy". №4,2003, pp. 32-37)

6. T.S. Kamalov, Current state and development trend of electric drives of industrial and agricultural installations, in Uzbekistan (Uzbek magazine "Problems of Informatics and Energy", №1,2004, pp.50-58)

7. E.I. Sokolov, A.Y.Baru, Y.L. Shindneset, Experience in the development and implementation of frequency converters for a controlled electric drive of pumping units of oil trunk pipelines, in Russian (Electrical Engineering,№7, 2004,pp.52-57)

8. A.D. Ernst, Self-starting of asynchronous electric motors, Tutorial. in Russian (Omsk, Publishing House of Omsk State University,46, 2006)

9. K.G. Abidov, Determination of the critical time for a power outage for self-starting of pumping units, in Uzbekistan (Journal "Problems of Energy and Resource Saving”,3,160,2017) 